\title{
Evolving Ethical Issues in Health and Mental Health
}

\author{
Shridhar Sharma \\ Emeritus Professor \\ National Academy of Medical Sciences \& \\ Institute of Human Behaviour \& Allied Sciences, Delhi.
}

\begin{abstract}
Ethics is the Science of morals in human conduct. However, ethics and morals are not same. The ethics is based on certain principles, which include 'Respect for Person and Justice'. This principle is not in total conformity with Hippocratic tradition, where Physician is given a 'Position of Paternalism'. The basic idea of 'justice' is that all human beings are equally valuable. Similarly, the principle of liberty is the right to self determination but what is the use of this right that can not be fulfilled. These basic principles are evolving and are constantly posing problems in every health care institution and are a challenge to every Physician.
\end{abstract}

Keywords: Ethics, morals, justice, autonomy, informed consent, ethics in health research.

\section{Introduction}

Ethics is the science of morals in human conduct, a moral principle or code (The Oxford Dictionary). However, ethics and morals are not same (1). Ethics go far beyond moral beliefs and values. Ethics is sustained by a purpose higher than ones own self interest. So the word 'ethics' encompasses the entire spectrum of good human conduct. Ethics as a branch of philosophy, deals with distinctions between right and wrong - with the moral consequences of human actions. Traditionally, ethics in medicine is guided by Hippocratic Principles where physician is placed in a position of "paternalism" $(2,3)$. The patient had no say on the issues related to treatment and all related circumstances like diagnosis. Physician was considered a confident and guardian of the secrecy of patients and Physicians' duty was to keep secrecy of knowledge and procedures followed in the management of patient's diseases.
Historically, the limitation in research was the classic 'do no harm principles'. During the last two millennium, science has grown tremendously and there are certainly changes in value system in society. However, ethics has not kept pace with the growth of science. It has been said that Science does not advance linearly in an orderly fashion but it jumps in different directions according to the scientific developments and sometimes the thinking is completely different than that of existing knowledge. Kuhn (1962) in his classic work, "the structure of scientific revolutions" calls these new ways as "thinking paradigm" (4). These new paradigms act as scientific lanes, as they capture the imagination of scientists, channelize their investigations for a time, until they in turn are substituted for a new paradigm. Thus, science advances and regenerates itself. These new scientific paradigms constantly influence our health care system. Concomitant with this growth in our knowledge, there is

Correspondence : Prof. Shridhar Sharma, D-127, Preet Vihar, Vikas Marg, Delhi-110092.

*The modified and updated paper is based on NAMS Golden Jubilee Lecture delivered at the Maharashtra Institute of Mental Health and BJ Medical College, Pune on April 26, 2011. 
another global development, which is taking place in the field of medical ethics. This new development was earlier synthesized by Ramsey (1970) in another classic work "The Patient as Person" (5). He advanced the proposition that "the physician-patient relationship" was lopsided towards the side of the physician and proposed that it should be the patient and not the physician, who should dictate the terms of the relationship in all the substantive matters. His proposition, completely opposed to the earlier Hippocratic tradition which dictated medical ethics. In fact, in the West, these ideas ushered in an 'ethical revolution' of bioethics (4-7). In the Hippocratic tradition, the physician was not only the healer and technician but also a custodian and guardian of the secrets of the patient $(8,9)$. In return for this power over the patient, the physician would undertake not to take advantage of the relative weakness of the patient and never to compromise his honour or that of his profession and respect the intrinsic value of human life. With the passage of time regretfully these values have slowly changed and diluted the ethical guidelines. A critical look on available ethical guidelines would reveal that today these refer more to professional etiquettes rather than the question of moral values. However, ethics go far beyond moral beliefs and values. Unlike moral values, the ethical codes are higher but constantly influenced by the changing sociopolitical situations and scientific advancements at a given time (5).

The basic principle in ethics includes "Respect for Person and Justice". This principle is not in total conformity with Hippocratic tradition, where Physician is given a position of paternalism $(2,3)$. The basic idea of 'Justice' is that all human beings are equally valuable. Yet it is a fact that people differ from one another and that such differences often justify unequal access to health care. Then there are other elements of justice which include equality, liberty and freedom. The principle of equality states that differences between individuals do not justify unequal access to healthcare due to their ability to pay, social status, cultural affiliation, education, place of residence and gender, etc. Similarly, the principle of liberty is the right to self determination but what is the use of this right when it can not be fulfilled (10). These basic evolving ethical issues are constantly posing problems in every health care institution and are a challenge to every physician involving the ideology of justice and healthcare (11).

But 'justice' also has a legal meaning which is especially relevant to Forensic Medicine, with its role "in conflict of interest". A respect for the individual's right of privacy and the maintenance of confidentiality are major concerns of the physicians performing forensic evaluations (12-13). The Physician maintains confidentiality to the extent possible given the legal context. Special attention is paid to any limitations on the usual precepts of medical confidentiality. An evaluation for forensic purposes begins with notice to the evaluee of any limitations on confidentiality. Information or reports derived from the forensic evaluation are subject to the rules of confidentiality as apply to the evaluation, and any disclosure is restricted accordingly. However, the ethical values are fast changing in globalized world in health field and every day we observe how they are violated.

Therefore, any system of ethical guidelines should evolve with time and the changing health care system. There is a growing global concern on the new ethical paradigm and the existing legal framework supporting its application to all disciplines of medicine. Some of the legal and ethical issues that is unable to keep pace with the rapid growth of science and technology in the changing socioeconomic condition, where "ideology of economy" is influencing every walk of human life. How the new ethical paradigms are evolving in the present environment of scientific and technological growth in a democratic society requires a careful evaluation. Similarly, what is the proper relationship amongest law, ethics and morality needs a careful attention. Ethics and codes of ethics are shaped by law but law is shaped by those codes to some extent and both 
are influenced by philosophical ethics (14).

To be able to appreciate this position where you are at any point in time, we must acknowledge and learn from the past - good and bad-or, one is likely to repeat the same. In 1946, after World War II(1939-45), during the Nuremberg trials, the Nuremberg Code for ethical conduct of research involving human subjects was developed (15). The trials highlighted highly unethical medical research conducted by Nazi doctors on many captive prisoners in the concentration camps during World War II. Much knowledge was gained from these studies. Should we not use this knowledge because of how it was gained, e.g. information on hypothermia - how long a person can survive in cold water before dying?

Nuremburg Code-1946 was developed consequent to Nuremburg trials at the end of the Second World War and published in 1949 (1516). It is one of the earliest codes of conduct and prescribes the ten basic principles for conducting research in human beings. One of the basic principles was voluntary consent.

The voluntary consent of the human subject is absolutely essential. This means that the person involved should have legal capacity to give consent; should be so situated as to be able to exercise free power of choice, without the intervention of any element of force, fraud, deceit, duress, overreaching, or other ulterior form of coercion; and should have sufficient knowledge and comprehension of the elements of the subject matter involved as to enable $\mathrm{him} /$ her to make an understanding and take an enlightened decision. This latter element requires that before the acceptance of an affirmative decision by the experimental subject there should be made known to him the nature, duration; and purpose of the experiment; the method and means by which it is to be conducted; all inconveniences and hazards reasonably to be expected; and the effects upon his health or person which may possibly come from his participation in the experiment. The duty and responsibility for ascertaining the quality of the consent rests upon each individual who initiates, directs or engages in the conduct of experiment or clinical study. It is a personal duty and responsibility which may not be delegated to another with impunity.

Later the World Medical Association (WMA) made recommendations guiding physicians for biomedical research involving human subjects. It was adopted by 18 th WMA held in Helsinki in June 1964 (17). This was subsequently amended by the 29th, 35th, 41st, 48th, 52nd, 59th and 64th WMA held at Tokyo in October, 1965, Venice in October, 1973, Hongkong in September, 1989, Somerset West, Republic of South Africa in October, 1996, Edinburgh in October, 2000, Seoul in October, 2008 and Fortaleza, Brazil in October, 2013, respectively. It states that- it is the mission of the physician to safeguard the health of the people. His or her knowledge and conscience are dedicated to the fulfillment of this mission. Subsequently the WMA Declaration of Geneva binds the physician with the words, "The health of my patient will be my first consideration", and the International Code of Medical Ethics declares that, "A physician shall act only in the patient's interest when providing medical care which might have the effect of weakening the physical and mental condition of the patient". Recently, WMA has revised Geneva declaration on participation in Capital Punishment on October 14, 2017 in Chicago in WMA General Assembly which states that "it is unethical for physicians to participate in capital punishment in any way or during any step of the execution process" (18).

In spite of these international declarations, we saw another major ethical violation in USA. In 1974, after the debacle of the syphilis natural history study conducted by the US Public Health Service on the participants of 'Tuskegee study of untreated Syphilis in the Negro Male' that withheld appropriate treatment even after antibiotics became available, the US enacted the National Research Act which established a 
National Commission for the Protection of Human Subjects of Biomedical and Behavioural Research. In 1979, this commission presented the Belmont Report (19). The US President, Bill Clinton apologized on behalf of the US government, to the surviving black participants and their surviving relatives on May 161997. This was done 65 years after the study was started.

Internationally, the Council for International Organization of Medical Sciences (CIOMS) in collaboration with WHO further developed "International Ethical Guidelines for Biomedical Research Involving Human Subjects" (http://www.cioms.ch/publications/ layoutguide2002.pdf) (20). These guidelines are updated regularly, the most recent updation has been undertaken in 2016 and published as "International Ethical Guidelines for Healthrelated Research Involving Humans" (21).

In 2005, UNESCO presented the Universal Declaration on Bioethics and Human Rights to further advance the principle of bioethics (21).

In view of the above and other related developments there is a need to explore issues related to value conflicts that have implications for ethical practice, which include:
a) Autonomy
b) Beneficence and Effectiveness
c) Non-Malfeasance
d) Confidentiality
e) Justice
f) Informed Consent
g) Information
h) Voluntarism

The principle of "autonomy of the person" and the principle of "beneficence and nonmalfeasance" in prevailing environment of 'justice' have also changed our understanding of ethics. Apart from these, with the growing social consciousness in the present day egalitarian society the principle of "autonomy of the person" and the principle of "beneficence (to do right) and non-malfeasance (to avoid causing evil or damage)" in the prevailing environment of justice have also evolved the understanding of ethics, specially after the Nuremberg trials in Germany and Tuskegee experiments in USA.

Despite the moral weightage of these new ethical guidelines witnessed in the western world, it is probable that these principles would not have obtained a powerful and accelerated importance, without the legal activism of the courts, powerful lobby of some NGOs within and outside UN, and the ubiquitous world media.

The new ethical paradigms and all the legal structures supporting their application are similar in all branches of Medicine.

\section{Autonomy}

The word autonomy denotes both "an ideal and an obligation" has also changed in recent times. The case for a physician to act paternalistically is followed by a counter argument which revolves around the respect of autonomy.

Autonomy, as an ideal, centres on a person's capacity for deliberation and reflection. Principle of autonomy presumes that a patient has a right to control his or her body and is consciously aware of having the capacity to make a decision with a sense of control. In medical ethics the word autonomy is commonly used to refer to an obligation. Persons ought to have independence to be free from coercion and inducements. This implies an obligation on the part of the physician to try to find out what the patient wants to achieve. This value has several implications in practice. It involves patient's mental capacity to understand and appreciate his free power and the context and the situation which may vary in:
a) Therapeutic situation
b) Research field
c) Forensic settings, which may include
i. Therapeutic situation
ii. Diagnostics-like Narcoanalysis in 
many criminal cases or in a recent case of DNA testing to prove paternity of a person.

\section{Beneficence and Effectiveness}

The principle of beneficence conveys an obligation to maximize benefits to an individual, community and minimize risk of harm in physical, psychological and social areas to a patient. This includes both a philosophical and scientific aspect (22). Recently Indian Council of Medical Research (ICMR) has published a comprehensive "National Ethical Guidelines for Biomedical and Health Research Involving Human Participants" and on related issues (ICMR, 2017) (22).

\section{Consent}

Consent is a decision making capacity of a subject or a patient and it should be assessed on a case by case basis but it has many contradictory elements. The case for the therapist to act paternalistically as enunciated in Hippocratic Oath is followed by the counterargument which revolves around the respect for autonomy of a person. A bridge between these two opposing positions is then offered which depends on viewing informed consent as a dynamic process. As part of this procedure it is made clear that while autonomy is the desired end-state, it is not the be-all and end-all of treatment. Autonomy includes Informed Consent after providing sufficient information without coercion. Capacity means to understand and appreciate consequences of participation.

\section{Consent to Treatment}

In Principle of autonomy, i.e. patient has the right to control his/her own body. It translates legally into assault, i.e. if 'medically touched' without consent (i.e. without consent to that touching). Informed Consent: practice of legal and ethical significance for persons living with illness.
Context of Informed Consent should include in Therapeutic situation, Research, and in Forensic setting.

Meaning of "informed consent" includes that in order to be fully legal, the patient's consent must be informed. Being informed implies cognition, willingness, consideration, intention and understanding. Opinion and choice cannot be final and acceptable unless they are based on knowledge and information provided before the choice is exercised. It supposes that no consent will be valid which does not depend on willingness.

Information must be communicated to the patient in a manner that is consistent with the patient's capacity to understand and in a form that maximizes such understanding. Consent is context-specific, i.e. it will be valid only if it has been given in respect of the relevant proposed treatment and diagnostic procedure and it is not a general consent.

Informed Consent on Diagnostic Assessment to Conduct Relevant Tests

Patient should be informed about the purpose, method, likely duration and expected benefit of diagnosis. Similarly, in therapeutic situation, patient should be explained about alternative modes of treatment, possible pain or discomfort, risks and side effects associated with each treatment modality. Patient has the right to refuse or stop treatment, except as provided in some situation. Patient shall never be invited or induced to waive the right to informed consent.

Consent includes - Competence to consent and it refers to patient's cognitive ability and mental capacity to process information. It is specific to a patient's ability at a given time, so that a patient may be competent to make a treatment decision at one time and not competent another time.

Consent does not always guarantee competence- consent to have a sex by a 16 -year 
girl or mentally sick patient is both legally and ethically wrong. Competence and rationality are not synonymous. Rationality is a characteristic of a person's decision making process and not of personal ability to make decisions. The informed consent of the subject of a forensic evaluation is obtained when possible. Where consent is not required, notice is given to the evaluee of the nature of the evaluation. If the evaluee is not competent to give consent, substituted consent is obtained in accordance with the laws of the jurisdiction. Consent is one of the core values of the ethical practice of medicine and psychiatry. It reflects respect for the person, a fundamental principle in the practice of medicine and forensic medicine. Obtaining informed consent is an expression of this request.

\section{Consent in Justice System}

It is important to appreciate that in particular situations, such as court ordered evaluations for competency to stand trial or involuntary commitment, consent is not required. In such a case, a physician should so inform the subject and explain that the evaluation is legally required and that if the subject refuses to participate in the evaluation, this fact will be included in any report or testimony.

Consent to treatment in a jail or prison or other criminal justice setting must be differentiated from consent to evaluation in general practice. Any physician providing treatment in these settings should be familiar with the judicial rules in regard to the patient's right to refuse treatment. There are some special situations like forced feeding in cases of hunger strike is ethically debatable. Similarly, sterilization of females in a mentally subnormal home is ethically unacceptable.

\section{What Does Consent Mean?}

We must all remember that there is no valid (ethical) consent without all elements satisfied but the question may be raised, how do we define each element? "There is no statutory statement but is taken to mean" capable of understanding in broad terms, the nature and purpose of the treatment. English law defines the elements in the following terms:

\section{Competence}

There is no 'statutory statement' but is taken to mean 'capable of understanding in broad terms the nature and purpose of the treatment'. Similarly, the element of information includes possible standards, 'Patient based': level of information necessary in order to allow patient to operate his/her autonomy or it could be 'Profession based': in that medical situation, based on 'duty of care'. It is necessary to distinguish fact of consent from evidence to consent, e.g. a complete Informed Consent Form (ICF) does not amount to the act of consent, only it is evidence as to consent. Implied consent cannot be used beyond that which is 'reasonable', implied consent (patient's consent 'unavailable' where reasonable man would consent), e.g. in case of unconscious patient. After a head injury or other medical conditions when the principle of necessity includes that doctor owes a 'duty of care'. For this, we must distinguish necessity/convenience. Today, in Emergency Department (ED) patient's attendants are continuing to rise in all hospitals and medical and nursing teams are working under considerable strain and their priorities are to save the life and limb of each patient. Sometimes this creates both administrative and ethical issues (23).

Consent to treatment includes the principle of autonomy, i.e. patient has the right to control his/her own body. Translates legally into assault, i.e. if 'medically touched' without consent. Collection of cerebro-spinal fluid without consent is an assault but collection of urine is not.

\section{Confidentiality}

The issue of confidentiality is another area 
which needs attention. Physicians should take precautions to assure that none of the confidential information they receive falls into the hands of unauthorized persons and Media for cheap publicity and marketing. Similarly, physicians should be familiar with the institutional policies in regard to confidentiality. Where no policy exists, physicians should clarify these matters with the institutional authorities and develop working guidelines to define their role.

The forensic situation often presents significant problems in regard to confidentiality. The psychiatrist, in particular must be aware of and alert to those issues of privacy and confidentiality presented by the particular forensic situation. Notice should be given as to any limitations. For example, before beginning a forensic evaluation, a physician should inform the evaluee that although they are physicians, they are not the evaluee's "doctor." Similarly, treating doctor should indicate for whom they are conducting the examination and what they will do with the information obtained as a result of the examination. Being retained by one side in a civil or criminal matter exposes the forensic doctor to the potential for unintended bias and the danger of distortion of their opinion. This becomes important in the field of psychiatry. The forensic psychiatrist practices specialty at the interface of two professions, each of which is concerned with human behaviour and each of which has developed its own particular institutions, procedures, values, and vocabulary. As a consequence, the practice of forensic psychiatry entails inherent potentials for complications, conflicts, misunderstandings and abuses. In custody cases, honesty and striving for objectivity requires that all parties be interviewed, if possible, before an opinion is rendered. Treating physicians should generally avoid agreeing to be an expert witness or to perform evaluations of their patients for legal purposes. The impression that a physician in a forensic situation might distort their opinion in the service of the party which retained them is especially detrimental to the profession and must be assiduously avoided. Honesty, objectivity and the adequacy of the clinical evaluation may be called into question when an expert opinion is offered without a personal evaluation.

Confidentiality is the obligation of a professional to keep in confidence the information shared by the patient during the course of consultation or treatment, except in cases of specific permission. The problems related to confidentiality when working with a multidisciplinary team and sharing of information through the electronic health record are other relevant issues which need careful attention. The treating team as well as the consultants specifically called for the patient come within the circle of confidentiality, and therefore, any disclosure of the information amongst them is permissible and does not involve its breach (24).

\section{Ethics and the Physician-Patient Relationship}

Ethics and physician-patient relationship are very important. This is due to rising patient expectation in democratic setup. One of the most important factors for this is the increased literacy and general awareness. Patients demand drugs for their each and every symptom. Along with this there is greater dissemination of scientific knowledge among the patients through commercial advertisements and increased access to internet. Thus, the doctor-patient relationship has become untenable due to social pressure of the patient and his family. Another factor which is compounding this problem is that the concept of confidentiality is disappearing among the physicians. All these issues have been examined by Frankena in his book "Ethics" (25).

Ethical Issues in Health Research include the principles of respect for individual, autonomy, humanism, compassion, principles of "Do Good unto Others", "Do no Harm", "Confidentiality" and "Informed Consent" are essential. 
If the patient is unable to give consent, the consent can be taken from the most appropriate person-guardian or legal authorities.

Legally incapacitated person may only undergo medical research where authorized and if permitted by legal representative or any authority or an individual authorized or designated under his nation's law. Legally incapacitated person may not undergo medical research unless it is expected to produce a direct and significant benefit to his health. By way of exception, national law may authorize research involving a legally incapacitated person which is not of direct benefit to his health when the person offers no objection, provided a research is to the benefit of persons in the same category and that the same scientific results cannot be obtained by research on persons who do not belong to this category. Pregnant or nursing women may not undergo medical research where their health and/or that of the child would not benefit directly even if this research is aimed at benefiting others.

\section{Ethical Issues in Human Genome}

Conflicts regarding legal and ethical ownership of the Human Genome is an emerging new area. Who should have access to personal genetic information and how, it will be used? Who will own and control genetic information and who will be benefited are the questions which need to be addressed (26).

\section{Ethics Committee}

Institutional Review Board (IRB) or Institutional Ethics Committee (IEC), review and approval are other issues in this area. Often IEC or IRB is present but not properly working. In this respect, ICMR and Drugs Controller General of India (DCGI) at the Centre for Drugs Standardization and Control Organization (CDSCO), Ministry of Health and Family Welfare, Government of India have developed some guidelines for biomedical research and drug-related clinical trials. IRBs and IECs protect the safety and welfare of human research participants. These bodies are responsible for providing an independent evaluation of proposed research studies, ensuring that the research does not proceed unless standards and regulations are met $(22,27)$.

It is important that membership of IRBs and IECs should include non-scientist, community representative, scientifically sound researcher, both by qualification and experience and a legal person. Similarly, Scientific Review Board should have both internal and external experts.

\section{Other Issues}

Euthanasia and Physician-assisted Suicide; participation in torture by physician and participation in legal execution of Death are all relevant but will need a separate paper for discussion.

\section{Conclusion}

In conclusion, it may be said that the ethical behaviour is based on the physician and individual sense of responsibility towards the patient. A physician should always keep in mind the boundaries of his relationship with his/her patient. He/she should be guided primarily by respect of patient's autonomy, justice and concern for his/her welfare and integrity.

\section{References}

1. Kant I (1967). Foundations of the metaphysics of morals. In: Ethical Theories: A Book of Readings. Melden AI, ed. Englewood Cliffs (NJ): Prentice Hall.

2. Hippocrates (1923). Collected Works (Vol. 2) With English translation by WHS Jones, St. Catherine's College, Cambridge (Loeb Classical Library). New York: GP Putnam's Sons, Ivi+336.

3. Hippocratic Oath (2002). Translated by Michael North. Available at 
http://www.nlm.nih.gov/hmd/greek/gree k-oath.html (Accessed on July 10, 2017).

4. Kuhn TS (1962). The Structure of Scientific Revolutions. Chicago: The University of Chicago Press.

5. Ramsey P (1970). The Patient as Person : Explorations in Medical Ethics, 2nd edn. New Haven: Yale University Press.

6. Sussan M (1974). Ethical components in the definition of health. Int J Health Ser 4: 539-548.

7. Reich WT, ed. (1995). Encyclopedia of Bioethics (revised edn.). London, New York: Simon \& Schuster MacMillan.

8. Edelstein L (1967). The Hippocratic Oath: Text, Translation, Interpretation. In: Ancient Medicine: The Selected Papers of Ludwig Edelstein. Temkin O, Temkin CL, eds. Baltimore: John Hopkins University Press, 3-63.

9. Beauchamp TL, Childress JF (1994). Principles of Biomedical Ethics, 4th edn. New York: Oxford University Press.

10. Nilstun T, Ohlsson R (1995). Should health care be rationed by age? Scand $J$ Soc Med 23: 81-84.

11. Engelhardt JR (1981). Health care allocations. Responses to the unjust, the unfortunate and the undesirable. In: Justice and Health Care. Schell, ed. Dord. Recjt, Boston, London: D Reidel Publishing Company, 121-137.

12. Simon RI, Wettstein RM (1997). Toward the development of guidelines for the conduct of forensic psychiatric examinations. J Am Acad Psychiatry Law 25: $17-30$.

13. Appelbaum PS (1997). A theory of ethics for forensic psychiatry. J Am Acad Psychiatry Law 25: 233-247.

14. Brassington I (2018). On the relationship between medical ethics and the law. Med Law Rev. doi: 10.1093/medlaw/fwx064. [Epub ahead of print]

15. Nittis S (1940). The authorship and probable dates of the Hippocratic Oath. Bull Hist Med 8: 1012-1021.

16. Nuremberg Code (1949). Trials of War Criminals before the Nuremberg Military Tribunals under Control Council Law No. 10, Vol. 2. Washington, DC: US Government Printing Office, 181-182.

17. WMA (1964). 18th World Medical Association, Helsinki, June 1964.

18. Gadde P, Akkaloori A (2018). The revised Declaration of Geneva, 2017, and India's contradictory legal provisions. Indian $\mathrm{J}$ Med Ethics. doi: 10.20529/ IJME.2018.008. [Epub ahead of print]

19. http://ohsr.od.nih.gov/guidelines/ belmont.html.

20. http://www.cioms.ch/publications/ layout_guide2002.pdf.

21. CIOMS (2016). International Guidelines for Health-related Research Involving Humans, Fourth Edn. Geneva: WHO Press.

22. ICMR (2017). National Ethical Guidelines for Biomedical and Health Research Involving Human Participants. New Delhi: Indian Council of Medical Research.

23. Gadd C, Jones C (2018). Accidents and ethics: a visual-narrative approach. Emerg $\mathrm{Nurse} 25(9): 35-41$. d o i : 10.7748/en.2018.e1727. 
24. Ashton K, Sullivan A (2018). Ethics and confidentiality for psychologists in academic health centers. J Clin Psychol Med Settings. doi:10.1007/s10880-0179537-4. [Epub ahead of print]

25. Frankena WK (1973). Ethics, 2nd edn. Englewood Cliffs (NJ): Prentice Hall.
26. Mathaiyan J, Chandrasekaran C, Davis S (2013). Ethics of genomic research. Perspect Clin Res 4(1):100-104.

27. Page SA, Nyeboer J (2017). Improving the process of research ethics review. Res Integ r P e e r R e v 2:14. doi : 10.1186/s41073-017-0038-7. eCollection 2017. 